\title{
The Life Changes Inventory - Revised
}

\author{
Bruce Greyson, M.D. \\ University of Virginia \\ Kenneth Ring, Ph.D. \\ Kentfield, CA
}

ABSTRACT: Characteristic psychological and behavioral changes are well recognized aftereffects of near-death experiences (NDEs). Although much valuable research into these aftereffects has been qualitative, Kenneth Ring (1984) developed a instrument to quantify value changes following an NDE. This instrument, eventually named the Life Changes Inventory (LCI), has evolved over the decades to reflect increased understanding of the nature and breadth of NDE aftereffects. However, the accumulated modifications of the original scale have never been published, and various researchers have continued to use superseded editions. This paper presents the Life Changes Inventory-Revised, a standardized version of this scale that embodies the accumulated knowledge culled from previous drafts of the LCI administered to disparate samples and from qualitative research into attitudinal changes reported by near-death experiencers. It is our hope that with this standardization of the LCI-R, it will replace earlier versions of the LCI and become the instrument of choice for future research into value changes associated with NDEs.

KEY WORDS: near-death experience; aftereffects; methodology; attitudes; measurement.

Near-death experiences (NDEs) are profound subjective experiences with mystical or transcendental features that some people report to have occurred during the course of a close brush with death. Although such experiences have been reported for centuries, they came to public attention and acquired the name "near-death experience" with the publication of Life After Life by Raymond Moody in 1975. Since that

Bruce Greyson, M.D., is Carlson Professor of Psychiatry at the University of Virginia. Kenneth Ring, Ph.D., is Professor Emeritus of Psychology at the University of Connecticut. Reprint requests should be addressed to Dr. Greyson at the Division of Personality Studies, Department of Psychiatric Medicine, University of Virginia Health System, P.O. Box 800152, Charlottesville, VA 22908-0152; e-mail: cbg4d@virginia.edu. 
time, much attention has been directed at efforts to validate the objectivity of NDEs and/or to elucidate psychological or physiological explanations for the experience.

However, there has been increasing interest in the reportedly transformative effects of NDEs on people who have them and on what these value-related changes may imply for the social, moral, and cultural meaning of NDEs. Characteristic psychological and behavioral changes are now well recognized as aftereffects of NDEs. These changes typically include an enhanced appreciation for everyday life, greater feelings of self-worth and self-acceptance, compassionate concern for others, reverence for all forms of life and a heightened sensitivity to the ecological health of the planet, devaluation of materialistic acquisitions, devaluation of competitive striving against others, a universal and inclusive spirituality, tremendous thirst for knowledge, conviction that life is meaningful, elimination of fear of death, conviction in sustained consciousness after death, and certainty of the existence of an ultimate, divine being (Ring and Valarino, 1998).

\section{Development of the Life Changes Inventory}

Although some reflections on the aftereffects of NDEs appeared in the initial half-decade after Moody's book was published (Greyson and Stevenson, 1980; Moody, 1977; Noyes, 1980; Ring, 1980), the first attempt to quantify these changes in personal values and interests was a Likert-type scale originally developed by Kenneth Ring and eventually named the Life Changes Inventory (LCI). The scale consisted of a number of items, all of which relate to a specific type of value. Although the individual items have evolved over the past two decades, the format has remained the same. Participants are asked to respond to each item in terms of a five-point scale indicating whether and to what degree they felt they had changed after their NDE. For example, the first item is: "Since my NDE, my desire to help others has ..." and the set of alternatives for this (and all other items) includes "strongly increased" (assigned a value of +2 ), "increased somewhat" (assigned a value of +1 ), "not changed" (assigned a value of 0 ), "decreased somewhat" (assigned a value of -1 ), or "strongly decreased" (assigned a value of -2 ). Thus, if a respondent felt that his or her desire to help others had strongly increased following the NDE, he or 
she would be credited with a score of +2 for that item. Although other scales have been developed for measuring changes in attitudes and values among NDErs (e.g., Greyson, 1983), the LCI has become the most widely-used instrument among near-death researchers.

The first published reference to what became the LCI was Charles Flynn's (1982) presentation of data from "a questionnaire administered by Kenneth Ring" to 21 near-death experiencers. That questionnaire was not named, but included items from the LCI and the LCI's characteristic Likert scoring key ranging from +2 for strongly increased to -2 for strongly decreased. Flynn reported the results of 20 items that he grouped into 6 factors, which he described as "types of transformation." These 6 factors were concern for others (including 7 scale items: desire to help others, compassion for others, ability to listen patiently, tolerance for others, insight into others, understanding others, and accepting others), death-related attitudes (2 items: fear of death and belief in afterlife), subjective transcendence ( 2 items: belief that life has inner meaning and feeling the inner presence of God), religiosity (4 items: interest in religion, religious feelings, interest in sacred things, and tendency to pray), materialism ( 3 items: desire for material things, desire for higher standard of living, and desire for wealth), and impression on others ( 2 items: desire to make a good impression and concern about what others think). Although all of the individual items that Flynn reported were included in Ring's original scale, it is not clear whether the 20 items that Flynn described represented the entirety of the scale administered or only those that loaded onto his 6 factors.

In a subsequent book, Flynn (1986) described what appeared to be data from the same instrument administered to the same 21 neardeath experiencers, but this time grouped into 4 factors: concern for others (including 8 items, the 7 mentioned above plus ability to express love openly), death-related attitudes (the same 2 items mentioned above), spirituality and religion (the 6 items from the subjective transcendence and religiosity factors mentioned above), and materialism ( 2 of the items mentioned above: desire for material things and desire for wealth). He also administered the same instrument to college students enrolled in his class on human transformation, deriving 5 somewhat different factors among that group.

Ring's first publication of the scale, which he called at that time the Life Changes Questionnaire (LCQ), was in connection with his presentation of the responses of 26 near-death experiencers in his book Heading Toward Omega (1984). The LCQ Ring described at that 
time included 42 items that he grouped into 5 factors variously referred to as value shifts, value clusters, or value domains: appreciation of life (including 2 items: appreciation of ordinary things and of nature), concern for others ( 8 items: desire to help others, compassion for others, ability to listen patiently, tolerance for others, ability to express love openly, insight into others, understanding others, and accepting others), concern with impressing others ( 3 items: desire to make a good impression, desire to be well-known, and concern about what others think), materialism (4 items: desire for material things, "living the good life," desire for high standard of living, and material success), and quest for meaning ( 6 items: interest in higher consciousness, in "what life is all about," a sense of purpose, belief that life has inner meaning, self-understanding, and sense of personal meaning).

A spirituality scale based in part on this 42 -item LCQ was subsequently used to assess changes in spirituality following ketamine psychedelic therapy for alcohol dependence (Krupitsky and Grinenko, 1998).

The term Life Changes Inventory (LCI) was first used by Ring in an article he published with Christopher Rosing (1990). In that article, Ring and Rosing described the responses of 74 near-death experiencers and 54 non-experiencers who had an interest in NDEs. That version of the LCI included 50 items that they grouped into 9 "personal value domains": appreciation for life, self-acceptance, concern for others, concern for impressing others, materialism, quest for meaning, spirituality, religiousness, and a new value cluster, concern with social/planetary issues, which Ring had derived from his increasing awareness of NDErs' sensitivity to ecological and global dangers. Neither the specific items nor the number of items that were included in each value domain was mentioned.

In Ring's subsequent book The Omega Project (1992), he compared the responses on the LCI of those 74 near-death experiencers and 54 non-experiencers who had an interest in NDEs with the responses of 97 persons who claimed to have had UFO encounters and 39 persons who had an interest in UFOs but made no such claim. At that time, he referred to the same 9 "principal value clusters" of the LCI, but again did not specify the individual items that comprised each value cluster.

The 50-item version of the LCI has since been used with several populations other than near-death experiencers, to measure important life changes associated with spiritual or transpersonal experiences (Brouillette, 1997; Carpenter, 1994; Chang, 1998; Hong, 1993; Palmer and Braud, 2002). 


\section{Derivation of the Life Changes Inventory - Revised}

Over the ensuing years, certain value domains were added to the LCI because they kept cropping up in interviews with experiences, such as concern with ecological or planetary issues. In developing the current Life Changes Inventory-Revised (LCI-R), we continued the process of eliminating individual items that appeared from experience with earlier versions of the scale to be ambiguous or interpreted inconsistently, and we added a few new items to clarify respondents' intentions. For example, many experiencers responded on earlier versions of the LCI to the item "religious feelings" by crossing out the word religious and writing in the word spiritual, or by failing to mark any answer but writing in, "Do you mean religious or spiritual feelings?" We therefore retained the original item about "religious feelings" and added a companion item about "spiritual feelings" to help respondents differentiate the two values. Other items were deleted from the LCI as experience showed them to be misinterpreted or unreliably interpreted by respondents. For example, the item asking about interest in "living the good life" was intended to imply a hedonistic existence, but was occasionally interpreted by some respondents as implying a virtuous life.

The grouping of individual items on the LCI-R into value clusters was arrived at by an iterative process, informed by experience with the scale, narrative descriptions by NDErs of their attitudinal changes, and preliminary factor analyses of responses to the LCI carried out independently by both authors on separate samples of NDErs. For example, factor analysis showed that two of the original value clusters, materialism and concern with impressing others, consistently loaded onto a single factor. Those two clusters were therefore merged into one cluster now labeled concern with worldly matters.

\section{Scoring the Life Changes Inventory - Revised}

The Life Changes Inventory-Revised consists of 50 items, presented in the Appendix. Each item presents a value that may have been affected by the respondent's near-death experience. As with previous versions of the LCI, respondents are asked to indicate whether each of these 50 values was strongly increased, somewhat increased, not changed, somewhat decreased, or strongly decreased as a result of their NDE. 
Scores for each of the 50 individual items may be of interest for various purposes. In addition, an Absolute Change Score may be calculated to reflect the global effect of the NDE. The Absolute Change Score is the mean of the absolute values of the 50 items. For example, if a respondent rated 25 items as "strongly increased" $(+2)$ and 25 items as "strongly decreased" $(-2)$, then the Global Change Score would be $\{[25 \times|(+2)|]+[25 \times|(-2)|]\} / 50=2$.

The LCI also yields scores for 9 values clusters that represent common domains of transformation following NDEs. The score for each of these 9 values clusters is the arithmetical mean of the items comprising that value cluster. For example, in a 2 -item value cluster, if a respondent rated one item as "somewhat increased" $(+1)$ and the second item as "somewhat decreased" $(-1)$, then the cluster score would be $[(+1)+(-1)] / 2=0$.

The items comprising the 9 value clusters are as follows:

Appreciation for life includes 4 items: appreciation of the "ordinary things of life" (item 3), "reverence for all forms of life" (item 8), "appreciation of nature" (item 17), and "sense of the sacred aspect of life" (item 26).

Self-acceptance includes 3 items: "feelings of self-worth" (item 5), "selfacceptance" (item 28), and "interest in self-understanding" (item 40).

Concern for others includes 10 items: "desire to help others" (item 1), "compassion for others" (item 2), "ability to listen patiently" (item 4), "tolerance for others" (item 10), "sensitivity to the suffering of others" (item 11), "ability to express love for others openly" (item 15), "insight into the problems of others" (item 16), "understanding of others" (item 25), "empathy with others" (item 37), and "acceptance of others" (item 47).

Concern with worldly achievement includes 7 items: "concern with the material things of life" (item 9), "interest in creating a 'good impression" (item 12), "competitive tendencies" (item 18), "ambition to achieve a high standard of living" (item 27), "desire to become a well-known person" (item 34), "interest in what others think of me" (item 44), and "interest in achieving material success" (item 46).

Concern with social/planetary values includes 5 items: "concern with the welfare of the planet" (item 21), "concern with the threat of nuclear weapons" (item 33), "concern with ecological matters" (item 38), "interest in political affairs" (item 45), and "concern with questions of social justice" (item 49). 
Quest for meaning/sense of purpose includes 4 items: "understanding of "what life is all about" (item 22), "personal sense of purpose in life" (item 23), "sense that there is some inner meaning to my life" (item 30), and "search for personal meaning" (item 48).

Spirituality includes 5 items: "concern with spiritual matters" (item

13), "desire to achieve a higher consciousness" (item 14), "spiritual feelings" (item 20), "belief in a high power" (item 24), and "inner sense of God's presence" (item 41).

Religiousness includes 4 items: "interest in organized religion" (item 7), "religious feelings" (item 19), "tendency to pray" (item 35), and "involvement with my church or religious community" (item 39). Appreciation of death includes 3 items: "fear of death" (item 32, scored negatively), "conviction that there is life after death" (item 43), and "interest in issues related to death and dying" (item 50).

Finally, the LCI-Revised includes 5 items that were not included in any of the 9 value clusters but were retained because we felt they represented common effects of NDEs that may be of interest as individual items. These 5 individual items were "interest in psychic phenomena" (item 6), "desire for solitude" (item 29), "involvement in family life" (item 31), "openness to the idea of reincarnation" (item 36), and "feelings of personal vulnerability" (item 42).

\section{Conclusion}

The Life Changes Inventory has been the most widely used instrument for quantifying changes in attitudes and values following near-death experiences. Its use has furthermore been expanded to the measurement of personal transformation following a variety of spiritually-oriented experiences and practices. The LCI has evolved over the decades to reflect growing experience with the scale and refined appreciation of the breadth of psychological and behavioral aftereffects typical among near-death experiencers. However, the accumulated modifications of the original scale have never been published, with the result that various researchers have continued to use superseded editions. Furthermore, there have been no studies of the validity or reliability of previous versions of the LCI, nor have norms been published for any populations.

We recognize and regret these lacunae and anticipate that they will be filled with appropriate psychometric analyses of the Life Changes 
Inventory-Revised. The LCI-R presented in this paper embodies the accumulated knowledge culled from administration of previous versions of the LCI to disparate samples and from three decades of qualitative research into attitudinal changes reported by near-death experiencers. We also believe that the LCI-R can easily be adapted for the measurement of personal transformation following a variety of spiritually-oriented experiences and practices in addition to NDEs, and we encourage researchers to do so. It is our hope that with this standardization of the LCI-R, it will replace earlier versions of the LCI and, pending the necessary psychometric studies, become the instrument of choice for future research into value changes associated with transformative experiences.

\section{References}

Brouillette, G. (1997). Reported effects of holotropic breathwork: An integrative technique for healing and personal changes. Unpublished doctoral dissertation, Institute of Transpersonal Psychology, Palo Alto, CA.

Carpenter, D. (1994). Spiritual experiences, life changes, and ecological viewpoints of contemporary pagans. Unpublished doctoral dissertation, Saybrook Institute, San Francisco, CA.

Chang, I. C. (1998). Chinese transpersonal education: Effects on high school teachers an general public adults in Taiwan. Unpublished doctoral dissertation, Institute of Transpersonal Psychology, Palo Alto, CA.

Flynn, C. F. (1982). Meanings and implications of NDEr transformations: Some preliminary findings and implications. Anabiosis: The Journal of Near-Death Studies, $2,3-14$.

Flynn, C. F. (1986). After the beyond: Human transformation and the near-death experience. Englewood Cliffs, NJ: Prentice-Hall.

Greyson, B. (1983). Near-death experiences and personal values. American Journal of Psychiatry, 140, 618-620.

Greyson, B., and Stevenson, I. (1980). The phenomenology of near-death experiences. American Journal of Psychiatry, 137, 1193-1196.

Hong, L. W. (1993). Evaluating a course in spiritual awakening: Changes in POI scores and self-report inventories. Unpublished doctoral dissertation, Institute of Transpersonal Psychology, Palo Alto, CA.

Krupitsky, E. M., and Grinenko, A. Y. (1998). Ten-year study of ketamine psychedelic therapy (KPT) of alcohol dependence. Heffter Review of Psychedelic Research, 1, 56-61.

Moody, R. A. (1975). Life after life. Covington, GA: Mockingbird Books.

Moody, R. A. (1977). Reflections on life after life. St. Simon's Island, GA: Mockingbird Books.

Noyes, R. (1980). Attitude change following near-death experiences. Psychiatry, 43, 234-242.

Palmer, G., and Braud, W. (2002). Exceptional human experiences, disclosure, and a more inclusive view of physical, psychological, and spiritual well-being. Journal of Transpersonal Psychology, 34, 29-59. 
Ring, K. (1980). Life at death: A scientific investigation of the near-death experience. New York, NY: Coward, McCann and Geoghegan.

Ring, K. (1984). Heading toward omega: In search of the meaning of the near-death experience. New York, NY: William Morrow.

Ring, K. (1992). The Omega Project: Near-death experiences, UFO encounters, and mind at large. New York, NY: William Morrow.

Ring, K., and Rosing, C. J. (1990). The Omega Project: An empirical study of the NDEprone personality. Journal of Near-Death Studies, 8, 211-239.

Ring, K., and Valarino, E. E. (1998). Lessons from the light: What we can learn from the near-death experience. New York, NY: Plenum.

\section{Appendix A}

\section{Life Changes Inventory - Revised}

A near-death incident may or may not bring about certain changes in an individual's life. We would like to know in what ways, if any, your near-death incident affected your life. In responding to the following items, please circle the appropriate alternative according to the instructions given below. Each statement should be understood as beginning with the phrase, "Since my near-death incident." For example, consider the following statement:

(Since my near-death incident), my interest in the field of medicine has ...

If you felt your interest had strongly increased, you would circle SI in the row following this statement. If you felt your interest had increased somewhat, you would circle I next to the statement. If your interest had not changed, you would circle NC. If your interest had decreased somewhat, you would circle D. Finally, if your interest had strongly decreased, you would circle SD. To summarize:

strongly increased $=\mathrm{SI}$

increased somewhat $=I$

not changed $=\mathrm{NC}$

decreased somewhat $=\mathrm{D}$

strongly decreased $=\mathrm{SD}$

Since my near-death incident, ... 
1. my desire to help others has

2. my compassion for others has

3. my appreciation for the "ordinary things of life" has

4. my ability to listen patiently to others has

5. my feelings of self-worth have

6. my interest in psychic phenomena has

7. my interest in organized religion has

8. my reverence for all forms of life has

9. my concern with the material things of life has

10. my tolerance for others has

11. my sensitivity to the suffering of others has

12. my interest in creating a "good impression" has

13. my concern with spiritual matters has

14. my desire to achieve a higher consciousness has

15. my ability to express love for others openly has

16. my insight into the problems of others has

17. my appreciation of nature has

18. my competitive tendencies have

19. my religious feelings have

20. my spiritual feelings have

21. my concern with the welfare of the planet has

22. my understanding of "what life is all about" has

23. my personal sense of purpose in life has

24. my belief in a higher power has

25. my understanding of others has

26. my sense of the sacred aspect of life has

27. my ambition to achieve a higher standard of living has

28. my self-acceptance has

29. my desire for solitude has

30. my sense that there is some inner meaning to my life has

31. my involvement in family life has

32. my fear of death has

33. my concern with the threat of nuclear weapons has

34. my desire to become a well-known person has

35. my tendency to pray has

36. my openness to the idea of reincarnation has

37. my empathy with others has
SI I NC D SD

SI I NC D SD

SI I NC D SD

SI I NC D $\quad$ SD

SI I NC D SD

SI I NC D SD

SI I NC $\mathrm{D} \quad \mathrm{SD}$

SI I NC D $\mathrm{SD}$

SI I NC D $\quad$ SD

SI I NC D SD

SI I NC D SD

SI I NC D SD

SI I NC D SD

SI I NC D SD

SI I NC D SD

SI I NC D SD

SI I NC $D$ SD

SI I NC D SD

SI I NC D SD

SI I NC $\mathrm{D} \quad \mathrm{SD}$

SI I NC D $\quad$ SD

SI I NC D SD

SI I NC D SD

SI I NC D SD

SI I NC D $\mathrm{SD}$

SI I NC D SD

SI I NC D SD

SI I NC D SD

SI I NC D $\quad$ SD

SI I NC D SD

SI I NC D SD

SI I NC D SD

SI I NC $\mathrm{D} \quad \mathrm{SD}$

SI I NC D $\quad$ SD

SI I NC D SD

SI I NC D SD

SI I NC D SD

(Continued) 


\section{Appendix A}

\section{(Continued)}

38. my concern with ecological matters has

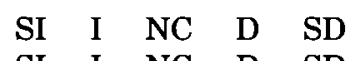

SI I NC D SD

39. my involvement with my church/religious community has

40. my interest in self-understanding has

41. my inner sense of God's presence has

42. my feelings of personal vulnerability have

43. my conviction that there is a life after death has

44. my interest in what others think of me has

45. my concern with political affairs has

46. my interest in achieving material success in life has

47. my acceptance of others has

48. my search for personal meaning has

49. my concern with questions of social justice has

50. my interest in issues relating to death and dying has

$\begin{array}{lllll}\text { SI } & \text { I } & \text { NC } & \text { D } & \text { SD } \\ \text { SI } & \text { I } & \text { NC } & \text { D } & \text { SD } \\ \text { SI } & \text { I } & \text { NC } & \text { D } & \text { SD } \\ \text { SI } & \text { I } & \text { NC } & \text { D } & \text { SD } \\ \text { SI } & \text { I } & \text { NC } & \text { D } & \text { SD } \\ \text { SI } & \text { I } & \text { NC } & \text { D } & \text { SD } \\ \text { SI } & \text { I } & \text { NC } & \text { D } & \text { SD } \\ & & & & \\ \text { SI } & \text { I } & \text { NC } & \text { D } & \text { SD } \\ \text { SI } & \text { I } & \text { NC } & \text { D } & \text { SD } \\ \text { SI } & \text { I } & \text { NC } & \text { D } & \text { SD } \\ \text { SI } & \text { I } & \text { NC } & \text { D } & \text { SD }\end{array}$

\section{Appendix B}

\section{Life Changes Inventory-Revised Scoring Instructions}

\section{Individual Items}

Scores for each of the 50 individual items in the LCI-Revised may be of interest for various purposes. Scores on each of the 50 individual items are calculated as follows:

Strongly increased $=+2$

Increased $=+1$

No change $=0$

Decreased $=-1$

Strongly decreased $=-2$

\section{Absolute Change Score}

In addition, an Absolute Change Score may be calculated to reflect the global effect of the near-death incident. The Absolute Change Score is the mean of the absolute values of the 50 items (that is, the numerical values from 0 to 2 , without regard to the plus or minus signs). For example, if a respondent rated 25 items as "strongly 
increased" $(+2)$ and 25 items as "strongly decreased" $(-2)$, then the Global Change Score would be:

$$
[(25 \times 2)+(25 \times 2)] / 50=2
$$

\section{Value Cluster Scores}

The LCI-Revised also yields scores for 9 value clusters that represent common domains of transformation following NDEs. The score for each of these 9 value clusters is the arithmetical mean of the items comprising that value cluster (that is, the numerical values ranging from +2 to -2 ). For example, in a 2 -item value cluster, if a respondent rated one item as "somewhat increased" $(+1)$ and the second item as "somewhat decreased" $(-1)$, then the cluster score would be:

$$
[(+1)+(-1)] / 2=0
$$

The items comprising the 9 value clusters are as follows:

Appreciation for life (4 items):

Item 3 = appreciation of the "ordinary things of life"

Item $8=$ reverence for all forms of life

Item $17=$ appreciation of nature

Item $26=$ sense of the sacred aspect of life

Self-acceptance (3 items):

Item $5=$ feelings of self-worth

Item $28=$ self-acceptance

Item $\mathbf{4 0}=$ interest in self-understanding

Concern for others (10 items):

Item $1=$ desire to help others

Item 2 = compassion for others

Item $4=$ ability to listen patiently

Item $10=$ tolerance for others

Item $11=$ sensitivity to the suffering of others

Item $15=$ ability to express love for others openly

Item $16=$ insight into the problems of others

Item $25=$ understanding of others

Item $37=$ empathy with others

Item $47=$ acceptance of others 
Concern with worldly achievement ( 7 items):

Item $9=$ concern with the material things of life Item 12 = interest in creating a "good impression"

Item $18=$ competitive tendencies

Item $27=$ ambition to achieve a high standard of living

Item $34=$ desire to become a well-known person

Item $44=$ interest in what others think of me

Item $46=$ interest in achieving material success

Concern with social/planetary values (5 items):

Item $21=$ concern with the welfare of the planet

Item $33=$ concern with the threat of nuclear weapons

Item $38=$ concern with ecological matters

Item $\mathbf{4 5}=$ interest in political affairs

Item 49 = concern with questions of social justice

Quest for meaning/sense of purpose (4 items):

Item 22 = understanding of "what life is all about"

Item $23=$ personal sense of purpose in life

Item $30=$ sense that there is some inner meaning to my life

Item $\mathbf{4 8}=$ search for personal meaning

Spirituality (5 items):

Item $13=$ concern with spiritual matters

Item $14=$ desire to achieve a higher consciousness

Item $20=$ spiritual feelings

Item $24=$ belief in a high power

Item 41 = inner sense of God's presence

Religiousness (4 items):

Item $7=$ interest in organized religion

Item $19=$ religious feelings

Item $35=$ tendency to pray

Item 39 = involvement with my church or religious community

Appreciation of death (3 items):

Item $32=$ fear of death (scored negatively, so that a response of "strongly increased" counts as -2 on this cluster score and "strongly decreased" counts as +2 ) 
Item $43=$ conviction that there is life after death

Item $\mathbf{5 0}=$ interest in issues related to death and dying

Note that there remain 5 items that are not included in the scoring of any value cluster:

Item 6 = interest in psychic phenomena

Item $29=$ desire for solitude

Item $31=$ involvement in family life

Item $36=$ openness to the idea of reincarnation

Item $\mathbf{4 2}=$ feelings of personal vulnerability 